\title{
The associations of humorous coping styles, affective states, job demands and job control with the frequency of upper respiratory tract infection
}

\author{
Authors: \\ Sibe Doosje ${ }^{1}$ \\ Martijn P.M. de Goede 2 \\ Lorenz J.P. van Doornen ${ }^{1}$ \\ Rens van de Schoot ${ }^{2}$ \\ Affiliations: \\ ${ }^{1}$ Department of Clinical \\ and Health Psychology, \\ Utrecht University, The \\ Netherlands \\ ${ }^{2}$ Department of \\ Methodology and \\ Statistics, Utrecht \\ University, The \\ Netherlands \\ Correspondence to: \\ Sibe Doosje \\ Email: \\ S.Doosje@uu.nl \\ Postal address: \\ Heidelberglaan 1, 3584 CS \\ Utrecht, The Netherlands \\ Dates: \\ Received: 30 Sept. 2009 \\ Accepted: 01 Dec. 2010 \\ Published: 23 May 2011 \\ How to cite this article: \\ Doosje, S., De Goede, \\ M.P.M., Van Doornen, \\ L.J.P., \& Van de Schoot, R. \\ (2011). The associations \\ of humorous coping \\ styles, affective states, \\ job demands and job \\ control with the frequency \\ of upper respiratory \\ tract infection. $S A$ \\ Journal of Industrial \\ Psychology/SA Tydskrif vir \\ Bedryfsielkunde, 37(2), Art. \\ \#863, 9 pages. doi:10.4102/ \\ sajip.v37i2.863
}

C) 2011. The Authors. Licensee: OpenJournals Publishing. This work is licensed under the Creative Commons Attribution License.
Orientation: There is some evidence that job demands and job resources such as job control and humorous coping may contribute to the risk of upper respiratory tract infections (URTI).

Research purpose: The purpose of this study was to test a model including these variables as well as job-related affect, in order to explore their role in the explanation of the frequency of upper respiratory tract infection.

Motivation of the study: This study has been conducted in order to extend our understanding of the role of traditional variables like job demands and job control with humorous coping styles and affective variables with regard to the explanation of the frequency of URTI.

Research design, approach and method: A sample of 2094 employees filled out questionnaires assessing job demands, job control, generic (MSHS-C), antecedent-focused and responsefocused humorous coping (QOHC) and job-related affect (JAWS).

Main findings: Job demands were indirectly related to the frequency of upper respiratory tract infections, mediated by their relationships with job control and negative job-related affect. Generic and response-focused humorous coping were less relevant for the explanation of the frequency of upper respiratory tract infections than the presumably 'healthy' antecedentfocused humorous coping style. The latter showed a negative association with negative jobrelated affect. The frequency of upper respiratory tract infections was better predicted by job control and negative job-related affect than by humorous coping, in the expected directions.

Practical/managerial implication: These findings may have practical relevance for the improvement of stress management interventions in organisations.

Contribution/value-add: Although it was shown that healthy humorous coping does contribute to decreases in upper respiratory tract infection, job demands, job resources and negative affective state seem the most important predictors.

\section{Introduction}

Upper respiratory tract infections (URTI) like the common cold and influenza are not only associated with procedures aimed at an increase of bodily hygiene - several studies have shown that psychological processes may also influence the risk to catch these common types of infection. However, these studies have not looked closely at job resources like job control and humorous coping styles and at affective states as predictors of URTI frequency, let alone that these variables have been incorporated into one model. Furthermore, previous studies have investigated generic humorous coping styles and have not looked at specific styles like antecedent-focused and response-focused humorous coping, which may theoretically differ in their effect on health, including URTI frequency.

The present study intends to fill these gaps, aiming to increase our understanding of the role of these occupational variables in their association with URTI frequency. A model incorporating job demands, job control, several styles of humorous coping and job-related affect as predictors of URTI frequency is tested, enabling investigation of the contribution of the separate variables as well as their interactions. The focus is on a test of the predictive value of generic and specific humorous coping styles for URTI frequency.

\section{Psychosocial variables, affective states and upper respiratory tract infections frequency}

The frequency of upper respiratory tract infections (URTI) may be predicted by general and jobrelated psychosocial variables. General demands increase the frequency of the common cold 
(Cohen, Tyrell, \& Smith, 1991, 1993). A similar relationship has been found for job-related demands (Hao, Duan \& Zhang, 2002; Mohren, Swaen, Borm, Bast, \& Galama, 2001). The adverse effects of these demands on URTI frequency may be due to their negative affective consequences. Several studies have indeed shown that negative affect is positively related to URTI frequency (e.g. Biondi \& Zannino, 1997; Cohen \& Williamson, 1991). Recently, Takkouche, Regueira and Gestal-Ottero (2001) have reported support for a negative association between positive affect and URTI frequency. However, job resources like job control and humorous coping styles may also play a significant role in adaptation to stress (Hobfoll, 2002) and should therefore be added to our model.

\section{Job control, humorous coping and affective states}

Job control has been proposed as an important job resource which acts as a buffer for job demands in Karasek's (1979) job demand-control model, which was later extended to the job demands-resources model (Demerouti, Bakker, Nachreiner \& Schaufeli, 2001). Job control is a key variable in this model, because it enables employees to decide how and when they do certain tasks. In some job types high job demands may be buffered by high job control (Karasek calls this an active job type). Another job resource may be humorous coping, which is an interesting coping style because - unlike many other coping styles - it is not only aimed at preventing or decreasing negative affective consequences resulting from stress, but also adding mirth to the coping equation (Doosje, De Goede, Van Doornen \& Goldstein, 2010). Several empirical studies have confirmed that generic humorous coping may serve this dual-purpose function because of its relationships with decreases in negative affect (e.g. Eggli, 1997; Olson, Hugelshofer, Kwon, \& Reff, 2005) and increases in positive affect (e.g. Anderson \& Arnoult, 1989; Martin, Puhlik-Doris, Larsen, Gray \& Weir, 2003). This is consistent with relief theory, stating that humour relieves tension in the individual (Cooper, 2008).

As the present study is dedicated to the associations of humorous coping with health dimensions, it should be mentioned that the traditional view of humorous coping as a generic concept has been challenged lately. Instead, responsefocused and antecedent-focused forms of humorous coping have been proposed, with possibly differential health effects. Combining Gross' (2001) work on two types of emotion regulation with the humorous coping concept, responsefocused and antecedent-focused humorous coping styles have been introduced and operationalised by Doosje et al. (2010). Antecedent-focused humorous coping is a kind of cognitive reappraisal, aimed at changing the possibly stressful meaning of a stressor at hand into a humorous one, thus neutralising it and preventing the development of a negative affective response. Response-focused humorous coping is used in a later stage of the stress process, when stress-induced negative affect has already taken place. In this type of coping response, humour is used to avoid or deny feelings of stress already present. In short, antecedent-focused humorous coping is used for stress prevention, whereas response-focused humorous coping is used for 'damage control' caused by stress. These two types of humorous coping styles may therefore differ in their associations with affective states as well as health status.

\section{Job control, humorous coping and upper respiratory tract infections frequency}

How are job resources related to URTI frequency? Job control was negatively associated with URTI frequency in studies by Hao et al. (2002) and Mohren et al. (2001). An interaction between job demands and job control has also been shown: high job demands and low job control groups show higher common cold frequency than groups high in job control (Van de Schoot, Hoytink, \& Doosje, 2009). The potential role of humorous coping in the association between demands and URTI frequency has been supported by studies that observed negative associations between generic humorous coping and common cold frequency for specific populations, namely mothers of newborns (Dillon \& Totten, 1989) and young cancer patients (Dowling, 2000). These humorous coping studies did not examine the impact of affective variables. Similarly, studies on the JD-R model do not typically include affective variables. It may be argued that affective states should play a pivotal role in the explanation of URTI frequency, because they relate to both job control and humorous coping and to URTI frequency. Although there is some evidence for differential health effects of responsefocused and antecedent-focused emotion regulation (Austenfeld \& Stanton, 2004; John \& Gross, 2004), no studies to date have explored their effect on URTI frequency. Also, associations between antecedent-focused and responsefocused humorous coping styles and physical health have not been investigated before.

\section{Common method variance}

Before presenting our research aims and questions, a possible bias in survey studies, common method bias, needs to be addressed. This is a methodological problem described by several authors (e.g. Lindell \& Whitney, 2001; Podsakoff, McKenzie, Lee \& Podsakoff, 2001). It can be ascribed to 'common method variance which is attributable to the measurement method rather than to the constructs the measures represent' (Podsakoff et al., 2001). However, the magnitude and even existence of this problem have been subject to debate (see Spector, 2006).

\section{Research aims, questions and hypotheses}

The main aim of the current study is to extend the job demand-resources model with affective states and humorous coping styles, assessing their separate and joint contribution to URTI frequency. Job demands are expected to show a positive relationship with URTI frequency and job control is expected to show a negative relationship with it (Hao et al., 2002; Mohren et al., 2001). Turning to the affective part of our model, positive affect is expected to relate negatively with URTI frequency (Takkouche et al. 2001), whereas negative affect is positively related with it (e.g. Biondi \& Zannino, 1997). No empirical evidence for a relationship of 
job demands and job control with affective parameters has been reported. These associations will therefore be explored. With regard to humorous coping, some studies showed weak associations between generic humorous coping and common cold frequency (Dillon \& Totten, 1989; Dowling, 2000). We expect to find these associations in our study, too. However, since generic humorous coping has shown relationships with positive and negative affect (Eggli, 1997; Olson et al., 2005), it is also possible that the association between humorous coping styles and URTI frequency is mediated by positive or negative affect. These relationships will therefore be explored in the present study. An interesting outcome of this study may be the differences between generic, antecedent-focused and response-focused humorous coping with regard to their associations with affective states and URTI frequency. Based on previous studies (Austenfeld \& Stanton, 2004; John \& Gross, 2004), antecedent-focused humorous coping may prove the healthiest humorous coping style of the three. This leads us to the following hypotheses:

- Hypothesis 1: Job demands are positively associated with URTI frequency (1a), whereas job control is negatively associated with it (1b).

- Hypothesis 2: Negative affect is positively related to URTI frequency (2a), whereas the reverse association is expected for positive affect (2b).

- Hypothesis 3: Generic humorous coping is weakly and negatively associated with URTI frequency.

- Hypothesis 4: Humorous coping styles are negatively related to negative affect (4a) and positively related to positive affect (4b).

- Hypothesis 5: Antecedent-focused humorous coping shows stronger negative associations with URTI frequency than generic (5a) and response-focused humorous coping $(5 b)$, possibly through their differential relationships with affect $(5 c)$.

Furthermore, the current study will explore the relationship between job demands, job control and affect. In addition, the relationships between different humorous coping styles, affect and URTI frequency and the relative contribution of all variables to the explanation of URTI frequency will be explored. We will also explore possible mediation patterns in the humorous coping-affect-URTI frequency relationship. Finally, common method bias will be addressed by testing the assumption that there is a basic underlying factor that will fit the model better than a model based on separate variables.

\section{Research design \\ Research approach}

This is a cross-sectional survey study studying several models incorporating job demands, job resources, job-related affect and the frequency of upper respiratory infections incidence (URTI).

\section{Research method}

\section{Participants}

Five hundred and twenty four first-year bachelor students of psychology at a Dutch university each selected four employees in their own social network, resulting in a quota sample of 2094 employees in a broad range of work settings in The Netherlands. Students gathered these data as part of an assignment for a methodology and statistics course on survey methods. They received grade points for the assignment. Inclusion criteria were employment for $50 \%$ of working time or more (actual mean working time was $62.6 \%$, $\mathrm{SD}=12.9)$, no present illnesses, an even division of men and women (1055 male participants and 1039 female participants) and a normal distribution of age (actual mean age was 40.1 years, $\mathrm{SD}=6.1$ ). Although we aimed at a balance between participants in terms of high and low education, there was an overrepresentation of highly educated participants $(47.6 \%$ in this study), compared to $28.9 \%$ in the Dutch working population (Statistics Netherlands, 2002).

\section{Measuring instruments}

Job demands and job control: Job demands were measured using four items, based on Karasek's (1985) job content instrument (adapted for Dutch populations by Furda, 1995). Its items refer to having to work too much and too fast, for example, 'How often do you have to put in extra effort to finish the job?' Answers were given on a 5-point scale ranging from 1 (never) to 5 (always). A similar scale was used for job control (e.g. 'Can you decide yourself how to execute your work?'), referring to the amount of job control experienced. This scale was originally developed by Karasek (1985, Dutch translation by Furda, 1995). A measurement model including both of these job characteristics as separate factors showed satisfactory fit to the data, $\chi^{2}(404)=85.5, \mathrm{NFI}=0.98$, $\mathrm{CFI}=0.98, \mathrm{RMSEA}=0.05$.

Job-related affect: Job-related affect has been measured by the 30-item Job Affective Well-Being Scale (JAWS), developed by Van Katwyk, Fox, Spector and Kelloway (2000), asking participants how they felt about their work in the previous month. Both arousal (high-low) and valence (positivenegative) dimensions have typically been included in the original scale, resulting in four subscales. Since this study is focused on the valence dimension, two subscales have been used, a 15-item positive job-related affect subscale (e.g. 'My job made me feel at ease' ') and a 15-item negative job-related affect subscale (e.g. 'My job made me feel intimidated'). Although positive and negative affect scales are strongly related in this study $(r=-0.85, p \leq 0.001)$, there are good reasons to consider positive and negative affect as separate affective dimensions (see Tellegen, Watson, \& Clark, 1999, for a discussion of the dimensionality of affect). To test the 2-factor solution for the JAWS, a measurement model including the two scales was conducted, $\chi^{2}(404)=5785.5$, NFI $=0.81$, CFI $=0.82$, RMSEA $=0.08$. Although the Root-Mean Square Error of Approximation (RMSEA) parameter shows adequate model fit, Normed Fit Index (NFI) and Comparative Fit Index (CFI) parameters are below 0.90, indicating a suboptimal fit. However, internal consistency of the positive and negative affect scales is very good (see Table 1 in the Results section for Cronbach's alphas), contributing to the conclusion that these two scales 
may be consistent ones. We also conducted an analysis based on the original 4-factor solution as proposed by Van Katwyk et al. (2000). This analysis resulted in an unidentified path model.

Humorous coping scales: Three humorous coping scales were used measuring generic, antecedent-focused and response-focused humorous coping styles. Also, an overall humorous coping style was computed, combining scores of these three humorous coping scales.

The coping scale of the Multidimensional Sense of Humor Scale (MSHS-C) measured generic humorous coping. This is an 8-item Likert-scale generic humorous coping scale (e.g. 'Uses of wit or humor help me master difficult situations'). It is part of a questionnaire also measuring other dimensions of a sense of humour (Thorson \& Powell, 1993).

Antecedent-focused humorous coping is one of the scales of the Questionnaire of Occupational Humorous Coping (QOHC), a 4-scale, 23-item questionnaire originally developed and tested by Doosje et al. (2010) with answers ranging from 1 (never) to 5 (very often). The 9-item antecedent-focused humorous coping scale (e.g. 'When I have to work more to finish something I am able to see the humor in the situation') refers to attempts to use humorous behaviour to cognitively reappraise a situation.

Response-focused humorous coping (e.g. 'When my work makes me feel tense, I make jokes to avoid that feeling') is also a part of the QOHC. This scale has five items, measuring the tendency to use humorous behaviour to ease, avoid or decrease stress or negative feelings that are already present.

Upper respiratory tract infection (URTI) frequency: Two types of URTI frequency were measured:

- common cold (e.g. 'How often have you experienced a common cold in the previous two months') frequency

- influenza ('flu', e.g. 'How often have you experienced the flu in the previous two months?') frequency.

Participants are asked how often $(1=$ never, $5=$ very often) they have experienced these infections of the upper respiratory tract.

\section{Research procedure}

Survey data were collected by students, who imputed the data in SPSS data files. After checking for errors and extreme values, scales were computed and descriptive, correlational and model analyses were performed.

\section{Statistical analysis}

For the descriptive and correlational analyses, SPSS 16.0.2 software was used, whereas structural equation modeling analyses were conducted using AMOS 16.1.0 software. Because of the high correlation between the two job-related affect scales, a collinearity test was performed ahead of the main multivariate analyses. In structural equation modeling (SEM) the $\chi^{2}$ parameter is usually employed as a goodness of fit parameter. However, since it is sensitive to sample size (Kline, 2005), additional fit indices have been used:

- Bentler-Bonett NFI (Bentler \& Bonett, 1980)

- CFI (Bentler, 1990)

- RMSEA (Browne \& Cudeck, 1993; Steiger, 1990).

To allow model comparison the Bayesian Information Criterion (BIC; Schwarz, 1978) was included, which takes both model fit and model complexity into account. When mediation or partial mediation was thought to be present, these indirect effects were tested using the Sobel test (Sobel, 1986). Common method bias was investigated by adding a method factor to the structural equation models.

\section{Results \\ Descriptive and correlational analyses}

Table 1 shows that internal consistency of all variables is adequate. The average values of job demands and job control are quite high, which is typical of an active job type (high job demands, high job control) population. In addition, positive job-related affect is high and negative job-related affect is low. Job demands are negatively related to positive jobrelated affect and positively related to negative job-related affect, whereas reverse and stronger associations have been established for job control.

Although we expected to find a positive relationship between job demands and URTI frequency (hypothesis

TABLE 1: Descriptive correclation and reliability analyses of job characteristics, humorous coping styles, job-related affect and upper respiratory tract infection frequency,

\begin{tabular}{|c|c|c|c|c|c|c|c|c|c|c|}
\hline Variables & Mean & SD & 1 & 2 & 3 & 4 & 5 & 6 & 7 & 8 \\
\hline \multicolumn{11}{|l|}{ Job characteristics } \\
\hline 1. Job demands & 3.57 & 0.64 & 0.73 & - & - & - & - & - & - & - \\
\hline 2. Job control & 3.94 & 0.72 & $0.23 * * *$ & 0.79 & - & - & - & - & - & - \\
\hline \multicolumn{11}{|l|}{ Humorous coping styles } \\
\hline 3. Generic humorous coping & 3.45 & 0.56 & $0.04^{*}$ & 0.03 & 0.79 & - & - & - & - & - \\
\hline 4. Antecedent-focused humorous coping & 2.72 & 0.61 & 0.02 & $0.06 * *$ & $0.51^{* * *}$ & 0.82 & - & - & - & - \\
\hline 5. Response-focused humorous coping & 2.55 & 0.73 & $0.07 * *$ & -0.02 & $0.52 * * *$ & $0.60 * * *$ & 0.82 & - & - & - \\
\hline \multicolumn{11}{|l|}{ Job-related affect } \\
\hline 6. Positive & 3.75 & 0.48 & $-0.05^{*}$ & $0.31 * * *$ & $0.05^{*}$ & $0.16 * * *$ & -0.01 & 0.91 & - & - \\
\hline 7. Negative & 1.88 & 0.54 & $0.13^{* * *}$ & $-0.20 * * *$ & 0.02 & $-0.06 * *$ & $0.09 * * *$ & $-0.85 * * *$ & 0.89 & - \\
\hline \multicolumn{11}{|l|}{ Upper respiratory tract infection frequency } \\
\hline 8. Common cold + influenza frequency & 1.88 & 0.72 & -0.01 & $-0.12 * * *$ & $0.04 *$ & 0.02 & $0.07 * * *$ & $-0.14 * * *$ & $0.16 * * *$ & - \\
\hline
\end{tabular}

SD, Standard Deviation

$N=2097$, internal consistency coefficients on the diagonal.

$*, p \leq 0.05$, two tails; ${ }^{* *}, p \leq 0.01$, two tails; ${ }^{* * *}, p \leq 0.001$, two tails 
1a), no such relationship can be demonstrated in the data. Hypothesis $1 b$ has been confirmed: job control and URTI frequency are negatively correlated. Also, negative jobrelated affect correlates positively with URTI frequency and positive job-related affect correlates negatively with it, confirming hypotheses $2 \mathrm{a}$ and $2 \mathrm{~b}$. Generic humorous coping is indeed very weakly associated with URTI frequency, but the sign of the coefficient is positive, not negative, disconfirming hypothesis 3 . Antecedent-focused humorous coping is negatively associated with negative job-related affect, whereas generic humorous coping is unrelated to it and response-focused humorous coping is positively related to it. This largely disconfirms hypothesis 4a. Hypothesis $4 \mathrm{~b}$, about a positive relationship between humorous coping styles and positive job-related affect, is confirmed for generic and antecedent-focused humorous coping styles, but not for response-focused humorous coping. Humorous coping styles do seem to be differentially related to job-related affect, which is preliminary evidence for hypothesis 5 , stating that humorous coping styles may relate to URTI frequency through their association with job-related affect.

\section{Demographic variables and collinearity}

Before proceeding to the path analyses, we will address two additional issues, namely:

- the role of demographic variables in the model

- the possible collinearity of the job-related affect scales.

With regard to the first issue, demographic variables like gender, age and educational level have been analysed in terms of their contribution to URTI frequency. There are no gender differences in URTI frequency, $t(2084)=0.29$, not significant. Age is negatively and weakly associated with URTI frequency $(r=-0.16, p \leq 0.001)$. People with high educational levels (advanced professional and university level, $M=1.81$, SD =0.72) have significantly lower URTI frequency than people with low education $(M=1.94$, $\mathrm{SD}=0.72), t(2088)=3.9, p \leq 0.001)$. With regard to the second issue, collinearity, positive and negative job-related affect are highly correlated. This means that this relationship may inflate variance in our model. To test this assumption, collinearity diagnostics have been computed in a multiple regression model including key independent variables like job demands, job control, humorous coping styles, the two job-related affect scales and the URTI frequency variable, the dependent variable. The results are satisfactory, since the Variance Inflation Factor (VIF) is 4.0 for positive job-related affect and 3.7 for negative job-related affect. This is way below the value of 10 suggested as a maximum for this test.

\section{Basic characteristics of the path analyses}

Structural equation modeling enables the exploration of the contribution of several humorous coping styles to an explanatory theoretical model for URTI frequency. Table 2 shows model fit parameters for the three different humorous coping styles and all humorous coping styles ('overall') combined. Although chi-square values are not significant for generic humorous coping (a formal requirement for interpretation), the large $N$ enables comparison with fit indexes for the other two humorous coping styles. NFI, CFI and RMSEA parameters are all within the required boundaries, meaning that all models show excellent fit to the data. Comparing the models, the BIC parameter (which computes model fit correcting for model complexity) is lowest for generic humorous coping, so at first sight this would seem the most successful humorous coping predictor for URTI frequency. We will return to generic and overall humorous coping later. In the next paragraph, we will present the findings with regard to antecedent-focused and response-focused humorous coping, which are expected to relate differentially to URTI frequency, possibly through differences in their relationships with positive and negative job-related affect (hypothesis 5).

\section{Comparing antecedent-focused and response- focused humorous coping}

The path models depicted in Figures 1 and 2 show an interesting pattern. Response-focused humorous coping (depicted in figure 1) is positively related to negative jobrelated affect and unrelated to positive job-related affect. Also, there is a small positive association between responsefocused humorous coping and URTI frequency, which improves model fit. Two possible mediation patterns are of interest here:

- one of response-focused humorous coping in the job demands-negative job-related affect relationship (1)

- one of negative job-related affect in the response-focused humorous coping-URTI frequency relationship (2).

The Sobel test for the first pattern shows that responsefocused humorous coping partially mediates the job demands-negative job-related affect relationship $(z=2.84$, $p \leq 0.01$, two-tailed). The second pattern shows that negative job-related affect acts as a partial mediator in the relationship

TABLE 2: Model fit and model comparison of several humorous copying styles in relation to the frequency of upper respiratory tract infection.

\begin{tabular}{|c|c|c|c|c|c|c|c|c|}
\hline \multirow[t]{3}{*}{$\mathrm{Nr}$} & \multirow[t]{3}{*}{ Type } & \multicolumn{7}{|c|}{ Model } \\
\hline & & \multicolumn{3}{|c|}{ Fit } & \multicolumn{4}{|c|}{ Comparisson } \\
\hline & & $\chi^{2}$ & $d f$ & $\chi^{2} / d f$ & NFI & CFI & RMSEA & BIC \\
\hline 1 & Response-focused (R) & 3.20 & 2 & 1.6 & 0.99 & 0.99 & 0.04 & 156.4 \\
\hline 2 & Antecedent-focused (A) & $11.3^{*}$ & 3 & 5.6 & 0.99 & 0.99 & 0.04 & 156.6 \\
\hline 3 & Generic (G) & 5.00 & 2 & 2.5 & 0.99 & 0.99 & 0.02 & 150.3 \\
\hline 4 & Overall $(R+A+G)$ & $112.2^{*}$ & 13 & 8.6 & 0.97 & 0.98 & 0.06 & 288.1 \\
\hline
\end{tabular}




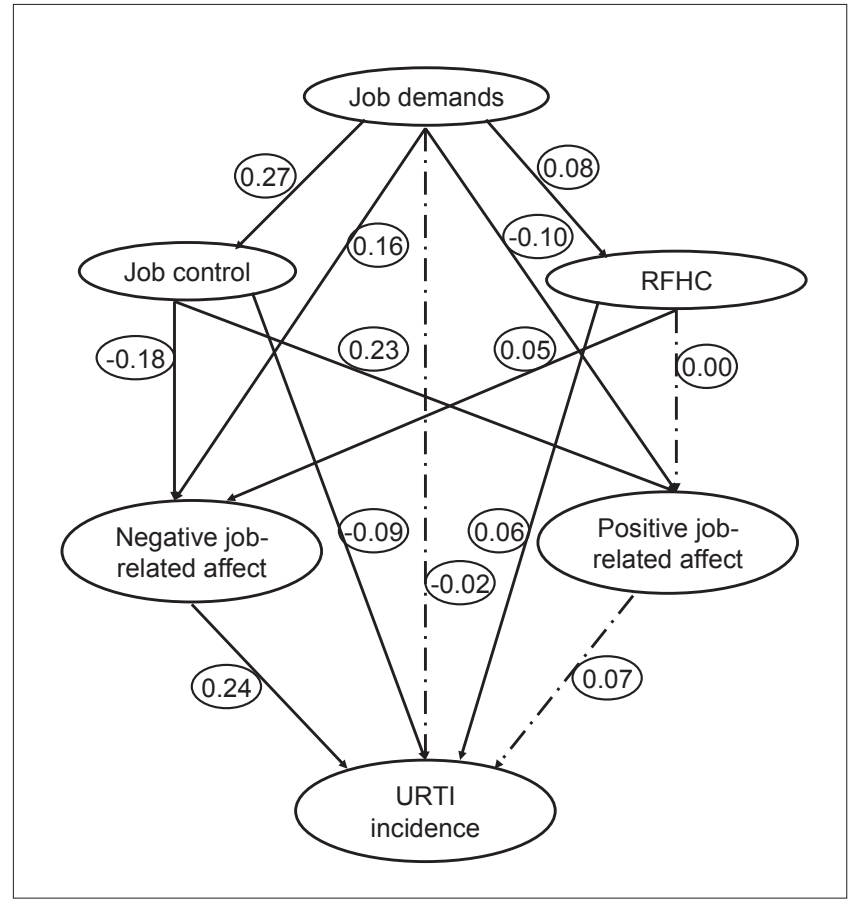

NOTE 1: Dashed lines indicate a non-significant path, for all other paths $p \leq 0.05$. NOTE 2: The correlation between both affect parameters has been included in the model, although the corresponding arrow has been removed for reasons of clarity.

FIGURE 1: Path model for response-focused humorous coping (RFHC) and upper respiratory tract infection (URTI) frequency, standardised coefficients.

between response-focused humorous coping and URTI frequency $(z=3.36, p \leq 0.001$, two-tailed $)$.

Antecedent-focused humorous coping (see Figure 2) shows a different associational pattern than response-focused humorous coping. It is unrelated to job demands and it is positively related to positive job-related affect. Also, this humorous coping style is negatively related to negative jobrelated affect (although regression coefficients are small). It is apparently related to URTI frequency by its association with negative job-related affect, but not by its association with positive job-related affect. Of all humorous coping styles, antecedent-focused humorous coping seems to bear the strongest relationship to URTI frequency, through its association with negative job-related affect, confirming this part of hypothesis 5 .

\section{Comparing generic and overall humorous coping}

Although generic humorous coping has shown the best model fit of all humorous coping styles, the associational patterns are quite different from those for antecedent-focused and response-focused humorous coping. Generic humorous coping shows a weak association with job demands $(\beta=0.04$, $p \leq 0.05)$, no association with negative job-related affect ( $\beta=0.02$, n.s.) and a weak association with positive jobrelated affect $(\beta=0.04, p \leq 0.05)$. Because of this associational pattern, generic humorous coping seems to have no predictive value for URTI frequency. A similar pattern exists for overall humorous coping, a combination of all three humorous coping styles: again, no association with negative job-related affect has been found. Also, weak associations

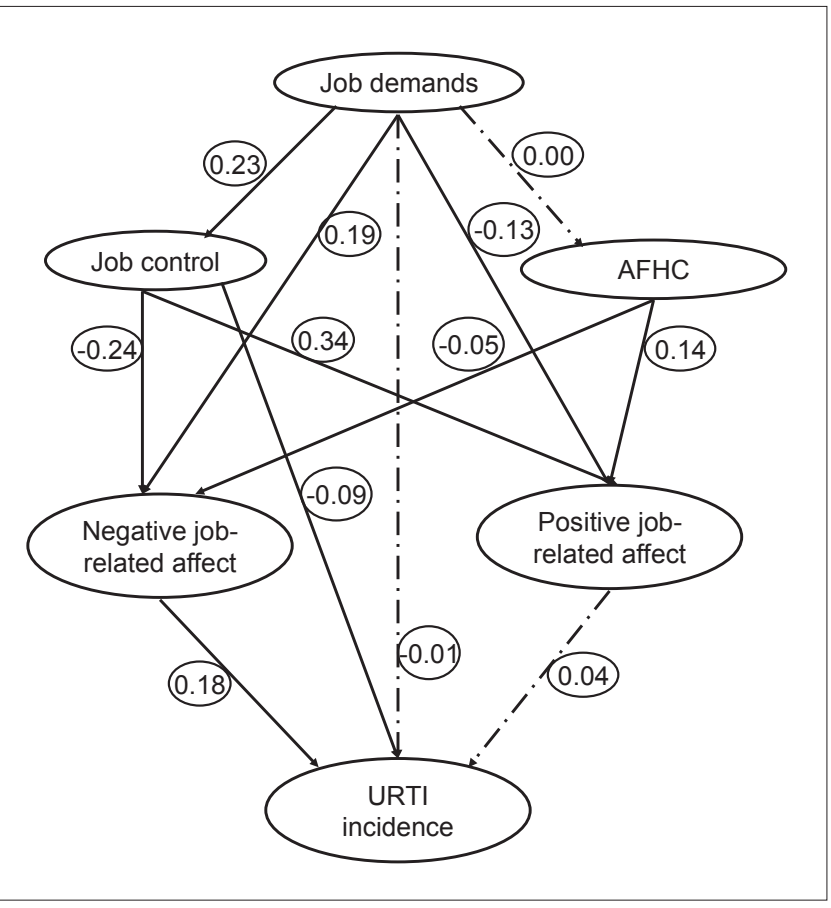

NOTE 1: Dashed lines indicate a non-significant path, for all other paths $p \leq 0.05$. NOTE 2: The correlation between both affect parameters has been included in the model, although the corresponding arrow has been removed for reasons of clarity.

FIGURE 2: Path model for antecedent-focused humorous coping (AFHC) and upper respiratory tract infection (URTI) frequency, standardised coefficients.

with job demands $(\beta=0.04, p \leq 0.05)$ and positive job-related affect $(\beta=0.08, p \leq 0.05)$ have been established.

\section{Comparison of the relative contribution of model variables}

Comparing the variables in the models, the right hand side of the models depicted in figures 1 and 2, seem much less successful predictors of URTI frequency than variables in the left-hand side of the model. Job control and negative job-related affect are related to each other and both are also related to URTI frequency. It is also clear that negative jobrelated affect is a better predictor than positive job-related affect and that job demands do show associations with URTI frequency, but mainly by its relationships with job control and negative job-related affect.

\section{Path analyses including demographic variables and common method bias}

Age and gender do not seem to contribute to the model (with low and non-significant $\beta$ 's). However, educational level does: there is a small but significant relationship to URTI frequency in the AFHC model $(\beta=0.04, p \leq 0.001)$. However, it is left out of the analyses, because model parameters are much less favorable for this model, $\chi^{2}(8)=954.2, \mathrm{NFI}=0.25, \mathrm{CFI}=0.24$, RMSEA $=0.23$.

No BIC parameter can be computed for this analysis. Finally, common method bias was counteracted by linking a new common variable to all other variables in the models presented here. This operation results in an inability to produce 
identifiable models. Therefore, we were unable to gather evidence for the assumption that there was common method bias in our data.

\section{Discussion}

\section{Summary of findings}

The main objective of this study was the test of a model explaining URTI frequency, including not only job demands and job control, but also humorous coping styles and jobrelated affect. It succeeded in building models fitting the data, combining relevant variables and their associations to URTI frequency, which have not been combined before. We were unable to replicate a direct effect of job demands on URTI frequency. We did find associations of job demands with negative and positive job-related affect and job control, suggesting that there may have been an indirect effect. This study showed that the favourable effect of job control on URTI frequency existed independently as well as by its association with negative job-related affect. Humorous coping styles were differentially related to URTI frequency. Although all humorous coping styles fitted well in models containing job characteristics and job-related affect, antecedent-focused humorous coping was more strongly related to parameters predicting URTI frequency than generic and responsefocused humorous coping. Antecedent-focused humorous coping, the style considered 'healthiest' beforehand, was related to job-related affect in the expected directions, associating with URTI frequency by a relationship with negative job-related affect. Generic humorous coping was related to positive job-related affect only, whereas responsefocused humorous coping was unrelated to positive jobrelated affect and positively related to negative job-related affect, which itself was positively related to URTI frequency. In this model, we also found a direct positive association between this humorous coping style and URTI frequency. Overall, humorous coping styles seemed to be poorer predictors of URTI frequency than job control and negative job-related affect. Antecedent-focused humorous coping and job control were positively associated. No common variance factor could be detected.

\section{Theoretical significance of the findings}

There is evidence from our study that antecedent-focused humorous coping is a 'healthier' humorous coping style than response-focused and generic humorous coping, which lends some support to the findings presented by Austenfeld and Stanton (2004) and John and Gross (2004), predicting different health effects of antecedent-focused and responsefocused emotion regulation. The (weak) association between antecedent-focused humorous coping and URTI frequency is no direct one. However, we were unable to demonstrate mediation effects here. Compared to the other two humorous coping styles, antecedent-focused humorous coping seems to comply best with the twofold aim of humorous coping:

- reduction in negative affect

- $\quad$ promotion of positive affect.
The associations between all humorous coping styles and job-related affect were generally small and weaker than reported in previous studies (e.g. Anderson \& Arnoult, 1989; Ward \& Kennedy, 2001). Our findings confirmed the weak associations between coping styles and health reported before in the review by Penley, Tomaka and Wiebe (2002). We could not replicate earlier studies reporting a direct relationship between job demands and common cold frequency (Hao et al., 2002; Mohren et al., 2001). The associations of job demands and URTI frequency were indirect and seemed to follow the path of job control and negative job-related affect.

\section{Alternative explanation of the findings}

The generally weak associations that we found may be due to certain characteristics of the research population. Although Mohren et al.'s (2001) study is comparable with regard to the number of participants (5896 individuals in theirs, 2094 in ours), mean age (40.9 in theirs, 40.1 in ours), they used a four-month period for common cold incidence, whereas this study used a two-month period. In their study, $46.6 \%$ of the population reported no common cold in that period; in our study, this was $62.8 \%$. Psychological health in our study was also excellent, as indicated by the high positive job-related affect and low negative job-related affect scores. Despite this affective bias, it is remarkable that the expected relationships with URTI frequency could still be found. Our population was high in job demands but also in job control, this may best be described as an active job type population, which Karasek (1979) already predicted should be in good health, a prediction which was confirmed in our study. The effect sizes in our study may be an underestimation. Increased variations in URTI frequency, affective states and educational level may increase them markedly. In fact, this was a healthy population from scratch, excluding less healthy employees with a higher risk of getting a common cold or influenza. Because low educational levels apparently increase health risks (e.g. Kunst et al., 2005), addressing the educational level bias could result in a research population with higher average URTI frequencies than in the population we studied.

\section{Methodological issues}

With regard to other methods and statistical procedures used in this study, the sampling method used in this study was not random. The advantage of quota sampling is that it may increase participants' willingness to cooperate in the study. However, the focus in this type of sampling is on the inclusion criteria (gender and age) and not on nonresponse bias. As we have seen, this has led to an overrepresentation of participants with high education. The possible consequences for other variables may be small, because many of the hypotheses we derived from previous research could be confirmed, indicating that sampling may have been valid. With regard to causality issues, no causal inferences can be made from our cross-sectional data - longitudinal studies will have to address this problem, although even they sometimes seem to show a causality bias, as concluded by Bakker and Demerouti (2007). In terms of common method 
variance, AMOS software was unable to detect it, confirming Spector's (2006) point of view on the issue. Of course this does not mean that it was not there.

\section{Future studies}

Although the incorporation of humorous coping styles into a job demands-resources (JDR) model has ended somewhat disappointing, it seems worthwhile to keep studying coping mechanisms as well as affective parameters in relation to occupational stress models (see Shimazu, Schaufeli, \& Taris, in press, for a successful example). Although weakly correlated, job control and antecedent-focused humorous coping showed a positive association. A promising avenue for future research would be the interaction of this type of humorous coping under varying job control conditions. Therefore, the role of a sense of humor in occupational health should not be ruled out in the future and may enrich more traditional work psychological models, like the JDR model. Especially Hobfoll's (2002) suggestion that proactive forms of coping (antecedent-focused humorous coping being one of them) seem much more prevalent nowadays, is a plea to keep following this path. We think it is also useful to continue combining JDR models with psychoneuroimmunological models in the future. Since this study did assess several successful predictors of URTI frequency, this line of research could be extended, for example, with the experimental approach to upper respiratory tract infection (see Cohen, 2005, for an overview). Also, because there is reason to believe that immunoglobulins in saliva (e.g. Ig-A) play a role in the chance to catch URTI (see Phillips et al., 2006), future studies may include this variable, preferably in a longitudinal design. An additional advantage of this type of design is that seasonal variations in URTI frequency may be included, which was not the case in our study. As a specific method, diary studies may be helpful, which may also learn us more about the frequency of humorous coping behaviors and their immediate and long-term effects. Since common infections like upper respiratory tract infections are so common and so hard to prevent, it seems worthwhile to continue examining the influence affective, job and humorous coping factors have on their occurrence. Another candidate for future research is cardiovascular functioning, which was one of the first physical health categories linked to the JDC model (see Rozanski et al., 2005, for a review). Therefore, it seems interesting to extend the model in this study to that research area.

\section{Practical implications of the study}

Although (especially antecedent-focused) humorous coping does seem to play a modest role in the frequency of upper respiratory tract infections, affecting both positive affect and negative affect variables, job control and negative affect seem more important predictors for URTI frequency. Practical implications of these outcomes may be relevant for the development of stress intervention programs, which in fact do seem to have some effect on infections of the upper respiratory tract (see Reid, Mackinnon \& Drummond, 2001, for an effect study). The focus of these interventions should preferably be on the management of negative affect and on increases in job control. The development or enhancement of humorous coping capabilities may also be part of these programs, with a focus on cognitive reappraisal of demanding situations before they get stressful, which is the aim of antecedent-focused humorous coping.

\section{References}

Anderson, C.A., \& Arnoult, L. H. (1989). An examination of perceived control, humor irrational beliefs, and positive stress as moderators of the relation between negative stress and health. Basic and Applied Social Psychology, 10(2), 101-117. doi:10.1207/s15324834basp1002_1

Austenfeld, J.L., \& Stanton, A.L. (2004). Coping through emotional approach: A new look at emotion, coping, and health-related outcomes. Journal of Personality, 72 1335-1363. doi:10.1111/j.1467-6494.2004.00299.x, PMid:15509285

Bakker, A.B., \& Demerouti, E. (2007). The job demands-resources model State of the art. Journal of Managerial Psychology, 22(3), 309-328. doi:10.1108/02683940710733115

Bentler, P.M. (1990). Comparative fit indexes in structural models. Psychological Bulletin, 107, 238-246. doi:10.1037/0033-2909.107.2.238, PMid:2320703

Bentler, P.M., \& Bonett, D.G. (1980). Significance tests and goodness of fit in the analysis of covariance structures. Psychological Bulletin, 88(3), 588-606. doi:10.1037/0033-2909.88.3.588

Biondi, M., \& Zannino, L.G. (1997). Psychological stress, neuro-immunomodulation, and susceptibility to infectious diseases in animals and man: A review. Psychotherapy and Psychosomatics, 66(1), 3-26. doi:10.1159/000289101, Psychotherapy

Browne, M.W., \& Cudeck, R. (1993). Alternative ways of assessing model fit. In K.A. Bollen J.S. Long (Eds.), Testing structural equation models (pp.136-162). Newbury Park, CA: Sage.

Cohen, S. (2005). The Pittsburgh common cold studies: Psychosocial predictors of susceptibility to respiratory infectious illness. International Journal of Behavioral Medicine, 12(3), 123-131. doi:10.1207/s15327558ijbm1203_1, PMid:16083315

Cohen, S., Tyrrell, D.A.J., \& Smith, A.P. (1991). Psychological stress and susceptibility to the common cold. New England Journal of Medicine, 325, 606-612. doi:10.1056 the common cold. New England Journal of

Cohen, S., Tyrrell, D.A.J., \& Smith, A.P. (1993). Negative life events, perceived stress, negative affect, and susceptibility to the common cold. Journal of Personality negative affect, and susceptibility to the common cold. Journal of Personality PMid:8421249

Cohen, S., \& Williamson, G.M. (1991). Stress and infectious disease in humans Psychological Bulletin, 109(1), 5-24. doi:10.1037/0033-2909.109.1.5, PMid:2006229

Cooper, C. (2008). Elucidating the bonds of workplace humor: A relational process model. Human Relations, 61(8), 1087-1115. doi:10.1177/0018726708094861

Demerouti, E., Bakker, A.B., Nachreiner, F., \& Schaufeli, W.B. (2001). The job demandsresources model of burnout. Journal of Applied Psychology, 86(3), 499-512. doi:10.1037/0021-9010.86.3.499, PMid:11419809

Dillon, K. M., \& Totten, M.C. (1989). Psychological factors, immunocompetence, and health of breast-feeding mothers and their infants. Journal of Genetic Psychology, 150(2), 155-162. doi:10.1080/00221325.1989.9914587, PMid:2769241

Doosje, S., De Goede, M.P.M., Van Doornen, L.P.J., \& Goldstein, J.H. (2010). Measurement of occupational humorous coping. Humor: International Journal of Humor Research, 23(3), 273-305.

Dowling, J. S. (2000). Sense of humor, childhood cancer stressors, and outcomes of psychosocial adjustment, immune function, and infection. Unpublished doctora dissertation, University of Massachusetts, Amsherst.

Eggli, P. (1997). Humor und Gesundheit: Eine Langschnittuntersuchung an Studienanfängerinnen über 'Sinn für Humor' als personale Ressource [Humor and Health: A cross sectional study of first-year students of 'sense of humor "as a personal resource], Unpublished Abhandlung zur Erlangung der Doktorwürde, Universität Zürich, Zürich, Switzerland.

Furda, J. (1995). Werk, persoon en welzijn: Een toets van het JD-C model [Work personality and well-being: A test of the JD-C model]. Unpublished doctoral dissertation, Utrecht University, the Netherlands.

Gross, J.J. (2001). Emotion regulation in adulthood: Timing is everything. Current Directions in Psychological Science, 10. 214-219. doi:10.1111/1467-8721.00152

Hao, Q., Duan, Z., \& Zhang, A. (2002). Relations between the occupational stress of nurses and their salivary immunoglobulin A level. Chinese Nursing Research, 16(4), 207-208.

Hobfoll, S.E. (2002). Social and psychological resources and adaptation. Review of General Psychology, 6(4), 307-324. doi:10.1037/1089-2680.6.4.307

John, O.P., \& Gross, J.J. (2004). Healthy and unhealthy emotion regulation: Personality processes, individual differences, and life span development. Journal of Personality 72, 1301-1333. doi:10.1111/j.1467-6494.2004.00298.x, PMid:15509284

Karasek, R.A. (1979). Job demands, job decision latitude and mental strain Implications for job redesign. Administrative Science Quarterly, 24, 285-308. doi:10.2307/2392498

Karasek, R.A. (1985). Job content instrument: Questionnaire and user's guide, revision 1.1. University of Southern California, Los Angeles.

Kline, R.B. (2005). Structural Equation Modelling. (2nd edn.). New York: The Guilford Press. 
Kunst, A., Bos, V., Lahelma, E., Bartley, M., Lissau, I., Regidor, E., et al. (2005). Trends in socioeconomic inequalities in self-assessed health in 10 European countries. International Journal of Epidemiology, 34, 295-305. doi:10.1093/ije/dyh342, PMid:15563586

Lindell, M.K., \& Whitney, D.J. (2001). Accounting for common method variance in cross-sectional research designs. Journal of Applied Psychology, 86, 114-121. doi:10.1037/0021-9010.86.1.114, PMid:11302223

Martin, R.A., Puhlik-Doris, P., Larsen, G., Gray, J., \& Weir, K. (2003). Individual difference in uses of humor and their relation to psychological well-being: Development of the Humor Styles Questionnaire. Journal of Research in Personality, 37(1), 48-75. doi:10.1016/S0092-6566(02)00534-2

Mohren, D.C., Swaen, G.M., Borm, P.J., Bast, A., \& Galama, J.M. (2001). Psychological job demands as a risk factor for common cold in a Dutch working population Journal of Psychosomatic Research, 50(1), 21-27. doi:10.1016/S0022 3999(00)00212-9

Olson, M.L., Hugelshofer, D.S., Kwon, P., \& Reff, R.C. (2005). Rumination and dysphoria: The buffering role of adaptive forms of humor. Personality and Individual Differences, 39, 1419-1428. doi:10.1016/j.paid.2005.05.006

Penley, J.A., Tomaka, J., \& Wiebe, J.S. (2002). The association of coping to physical and psychological health outcomes: A meta-analytic review. Journal of Behavioral Medicine, 25, 551-603. doi:10.1023/A:1020641400589, PMid:12462958

Phillips, A.C., Carroll, D., Evand, P., Bosch, J.A., Clow, A., Hucklebridge, F., Der, G. (2006) Stressful life events are associated with low secretion rates of immunoglobulin $\mathrm{A}$ in saliva in the middle aged and elderly. Brain, Behavior, and Immunity, 20 191-197. doi:10.1016/j.bbi.2005.06.006, PMid:16055305

Podsakoff, P.M., MacKenzie, S.B., Lee, J.-Y, \& Podsakoff, N.P. (2003). Common method biases in behavioural research: A critical review of the literature and recommended remedies. Journal of Applied Psychology, 88(5), 879-903. recommended remedies. Journal of Applied

Reid, M.R., Mackinnon, L.T., \& Drummond, P.D. (2001). The effects of stress management on symptoms of upper respiratory tract infection, secretory 作 51, 721-728. doi:10.1016/S0022-3999(01)00234-3

Rozanski A., Blumenthal J.A., Davidson K.W., Saab P.G., Kubzansky L. (2005). The epidemiology, pathophysiology, and management of psychosocial risk factors in cardiac practice: the emerging field of behavioral cardiology. Journal of the American College of Cardiology, 45, 637-51. doi:10.1016/j.jacc.2004.12.005 PMid:15734605
Schwarz, G. (1978). Estimating the dimension of a model. Annals of Statistics, 6 , 461-465. doi:10.1214/aos/1176344136

Shimazu, A., Schaufeli, W.B., \& Taris, T.W. (in press). How does workaholism affect worker health and performance? The mediating role of coping. International Journal of Behavioral Medicine. Epub ahead of publication.

Sobel, M.E. (1986). Some new results on indirect effects and their standard errors in covariance structure models. In N.B. Tuma (Ed.), Sociological Methodology (pp. 159-186). San Francisco: Jossey-Bass.

Spector, P.E. (2006). Method variance in organizational research: Truth or urban legend? Organizational Research Methods, 9(2), 221-232. doi:10.1177/1094428105284955

Statistics Netherlands (2001). Working population by educational level. Voorburg/ Heerlen: Centraal Bureau voor de Statistiek.

Steiger, J.H. (1990). Structural model evaluation and modification: An interval estimation approach. Multivariate Behavioral Research, 25, 173-180. doi:10.1207/s15327906mbr2502_4

Takkouche, B., Regueira, C., \& Gestal-Otero, J. J. (2001). A cohort study of stress and the common cold. Epidemiology, 12(3), 35-349.

Tellegen, A., Watson, D., \& Clark, L. A. (1999). On the dimensional and hierarchical structure of affect. Psychological Science, 10(4), 297-303. doi:10.1111/14679280.00157

Thorson, J. A., \& Powell, F. C. (1993). Development and validation of a multidimensiona sense of humor scale. Journal of Clinical Psychology, 49(1), 13-23. doi:10.1002/1097-4679(199301)49:1<13::AID-JCLP2270490103>3.0.CO;2-S

Van de Schoot, R., Hoytink, H., \& Doosje, S. (2009). Van onderzoeksvraag naar resultaten: Nulhypothesetoetsing versus Bayesiaanse modelselectie. [Directly evaluating expectations or testing the null hypothesis. Null hypothesis testing versus Bayesian Model selection.]. De Psycholoog, april, 196-203.

Van Katwyk, P.T. Fox, S., Spector, P. E., \& Kelloway, E. K. (2000). Using the JobRelated Affective Well-Being Scale (JAWS) to investigate affective responses to work stressors, Journal of Occupational Health Psychology, 5(2), 219-230. doi:10.1037/1076-8998.5.2.219, PMid:10784286

Ward, C. \& Kennedy, A. (2001) Coping with cross-cultural transition Journal of CrossCultural Psychology, 32(5), 636-642. doi:10.1177/0022022101032005007 